\title{
Association of HLA Genotype and Fulminant Type 1 Diabetes in Koreans
}

\author{
Soo Heon Kwak ${ }^{1}$, Yoon Ji Kim ${ }^{1}$, Jeesoo Chae ${ }^{2}$, Cue Hyunkyu Lee ${ }^{3}$, Buhm Han ${ }^{3,4}$, Jong-Il Kim², \\ Hye Seung Jung ${ }^{1}$, Young Min Cho ${ }^{1,5}$, Kyong Soo Park ${ }^{1,5,6 *}$ \\ ${ }^{1}$ Department of Internal Medicine, Seoul National University Hospital, Seoul 03080, Korea, \\ ${ }^{2}$ Department of Biomedical Sciences, Seoul National University College of Medicine, Seoul 03080, Korea, \\ ${ }^{3}$ Asan Institute for Life Sciences, Asan Medical Center, Seoul 05505, Korea, \\ ${ }^{4}$ Department of Convergence Medicine, University of Ulsan College of Medicine, Seoul 05505, Korea, \\ ${ }^{5}$ Department of Internal Medicine, Seoul National University College of Medicine, Seoul 03080, Korea, \\ ${ }^{6}$ Department of Molecular Medicine and Biopharmaceutical Sciences, Graduate School of Convergence Science and Technology, \\ Seoul National University, Seoul 03080, Korea
}

\begin{abstract}
Fulminant type 1 diabetes (T1DM) is a distinct subtype of T1DM that is characterized by rapid onset hyperglycemia, ketoacidosis, absolute insulin deficiency, and near normal levels of glycated hemoglobin at initial presentation. Although it has been reported that class II human leukocyte antigen (HLA) genotype is associated with fulminant T1DM, the genetic predisposition is not fully understood. In this study we investigated the HLA genotype and haplotype in 11 Korean cases of fulminant T1DM using imputation of whole exome sequencing data and compared its frequencies with 413 participants of the Korean Reference Panel. The HLA-DRB1*04:05-HLA-DQB1*04:01 haplotype was significantly associated with increased risk of fulminant T1DM in Fisher's exact test (odds ratio [OR], 4.11;95\% confidence interval [CI], 1.56 to 10.86; $p=0.009$ ). A histidine residue at HLA-DR 31 position 13 was marginally associated with increased risk of fulminant T1DM (OR, 2.45; 95\% $\mathrm{Cl}, 1.01$ to 5.94; $\mathrm{p}=0.054$ ). Although we had limited statistical power, we provide evidence that HLA haplotype and amino acid change can be a genetic risk factor of fulminant T1DM in Koreans. Further large-scale research is required to confirm these findings.
\end{abstract}

Keywords: autoimmunity, fulminant type 1 diabetes, haplotypes, HLA antigens, imputation, whole exome sequencing

\section{Introduction}

Fulminant type 1 diabetes (T1DM) is a distinct subtype of T1DM that is characterized by rapid onset of hyperglycemia and ketoacidosis with absolute deficiency in insulin secretion, and near normal glycated hemoglobin (HbAlc) level at initial presentation [1]. It was first described in 2000 by Imagawa et al. [2], and was defined as diabetes with remarkably rapid onset (within a few days) and absolute destruction of pancreatic $\beta$-cells. The prevalence of fulminant T1DM is not uncommon and it is estimated to account for $7.1 \%$ of all newly diagnosed T1DM cases in Korea [3].

The detailed pathogenesis of fulminant T1DM is not fully understood. Both genetic and environmental factors, and their interaction contribute to the development of fulminant T1DM. Regarding genetic factors, it has been reported that human leukocyte antigen (HLA) genotype and the HLADR4 - HLA-DQ4 haplotype play a crucial role in the predisposition to fulminant T1DM. Specifically, the HLA-DRB1* 04:05-HLA-DQB1*04:01 haplotype was associated with fulminant T1DM by an odds ratio (OR) of 2.9 in Japanese cases $(n=207)$ and controls $(n=325)$ [4]. In addition, the HLA-DRB1*09:01-HLA-DQB1*03:03 haplotype was also associated with fulminant T1DM by an OR of 2.1 [4]. However, these findings have not been replicated in other populations. Recently, three amino acid positions (HLA-DR $\beta 1$ position 13 , position 71 , and HLA-DQ $\beta 1$ position 57 ) in the HLA-DR and HLA-DQ molecules were shown to be significantly associated with T1DM in Europeans [5]. They 
explained $90 \%$ of the phenotypic variance in the HLA-DRB1 -HLA-DQA1-HLA-DQB1 locus.

In this study, we investigated the HLA-DRB1-HLADQB1 haplotype and amino acid residues at HLA-DR $\beta 1$ position 13 and position 71, and HLA-DQ $\beta 1$ position 57 in 11 Korean fulminant T1DM cases and compared their frequencies with that of the Korean Reference Panel obtained from 413 participants in the general population [6].

\section{Methods}

\section{Study participants}

A total of 11 cases of fulminant T1DM were identified at Seoul National University Hospital between January 2005 and December 2011 and written informed consent was acquired from the participants. The study protocol was approved by the Institutional Review Board (IRB) of the Clinical Research Institute of Seoul National University Hospital (IRB No. 0412-138-017 and 1205-130-411). Peripheral blood DNA was used for massive parallel sequencing.

\section{Whole exome sequencing}

Whole exome capture was performed with the SureSelect Human All Exon Kit V4+UTRs (Agilent Technologies, Santa Clara, CA, USA) and massive parallel sequencing was performed with the HiSeq 2000 Sequencing System (Illumina Inc., San Diego, CA, USA). The sequence reads were mapped and aligned to a human reference genome using BurrowWheeler Alignment software version 0.7.12 [7]. The Genome Analysis Toolkit 3.0 HaplotypeCaller was used to identify single nucleotide variations, insertions, and deletions by multi-sample calling method [8].

\section{HLA imputation}

For HLA genotype imputation, SNP2HLA software version 1.0.3 was used with default options [9]. Single nucleotide variations, amino acid residues, and four-digit classical HLA alleles of eight HLA genes in chromosome 6 were imputed. HLA haplotype was inferred with Beagle version 3.0.4 [10]. Imputation was performed based on whole exome sequence genotype data after quality control and as reference, the pan-Asian $(n=530)$ pre-built reference panel provided by the SNP2HLA was used [11]. An

Table 1. Clinical characteristics and HLA diplotypes of study participants

\begin{tabular}{|c|c|c|c|c|c|c|c|c|c|c|c|c|}
\hline $\begin{array}{l}\text { Patient } \\
\text { No. }\end{array}$ & $\begin{array}{l}\text { Age } \\
(y)\end{array}$ & Sex & $\begin{array}{l}\text { Diabetic } \\
\text { ketoacid } \\
\text { osis }\end{array}$ & $\begin{array}{c}\text { Body } \\
\text { mass } \\
\text { index } \\
\left(\mathrm{kg} / \mathrm{m}^{2}\right)\end{array}$ & $\begin{array}{l}\text { Plasma } \\
\text { glucose } \\
\text { (mg/dL) }\end{array}$ & $\begin{array}{c}\text { HbA1c } \\
(\%)\end{array}$ & $\begin{array}{c}\text { Fasting } \\
\text { C-peptide } \\
\text { (ng/mL) }\end{array}$ & $\begin{array}{c}\text { Anti-GAD } \\
\text { antibody }\end{array}$ & $\begin{array}{c}\text { HLA-DRB1- } \\
\text { HLA-DQB1 } \\
\text { diplotype }\end{array}$ & $\begin{array}{c}\text { HLA-DR } \beta 1 \\
\text { position } \\
1^{\mathrm{a}}\end{array}$ & $\begin{array}{c}\text { HLA-DR } \beta 1 \\
\text { position } \\
71^{\mathrm{a}}\end{array}$ & $\begin{array}{l}\text { HLA-DQ } \beta 1 \\
\text { position } \\
57^{\mathrm{a}}\end{array}$ \\
\hline 1 & 58 & M & Yes & 19.9 & 536 & 6.5 & 0.1 & Negative & $\begin{array}{l}* 04: 05-* 04: 01 / \\
* 04: 05-* 04: 01\end{array}$ & $\mathrm{HH}$ & RR & DD \\
\hline 2 & 28 & $\mathrm{~F}$ & Yes & 19.0 & 455 & 5.8 & 0.1 & Negative & $\begin{array}{l}* 12: 02-* 03: 01 / \\
* 04: 05-* 04: 01\end{array}$ & $\mathrm{GH}$ & RR & $\mathrm{DD}$ \\
\hline 3 & 45 & M & Yes & 19.8 & 460 & 8.1 & 0.1 & Negative & $\begin{array}{l}* 04: 01 — * 03: 01 / \\
* 07: 01-* 03: 03\end{array}$ & $\mathrm{YH}$ & RK & DD \\
\hline 4 & 31 & $\mathrm{~F}$ & Yes & 28.5 & 416 & 6.3 & $<0.1$ & Negative & $\begin{array}{l}* 08: 03-* 06: 01 / \\
* 15: 02-* 06: 01\end{array}$ & GR & RA & DD \\
\hline 5 & 27 & M & Yes & 25.3 & 400 & 6.9 & 0.1 & Negative & $\begin{array}{l}* 04: 06-* 03: 02 / \\
* 08: 03-* 06: 01\end{array}$ & $\mathrm{GH}$ & RR & DA \\
\hline 6 & 48 & M & Yes & 19.8 & 681 & 6.2 & 0.1 & Negative & $\begin{array}{l}* 09: 01-* 03: 03 / \\
* 12: 02-* 03: 01\end{array}$ & GF & RR & DD \\
\hline 7 & 28 & $\mathrm{~F}$ & Yes & 19.5 & 900 & 6.1 & $<0.1$ & Negative & $\begin{array}{l}* 03: 01-* 02: 01 / \\
* 13: 02-* 06: 09\end{array}$ & SS & EK & AV \\
\hline 8 & 36 & $\mathrm{~F}$ & Yes & 22.1 & 506 & 5.9 & 0.1 & Negative & $\begin{array}{l}* 04: 05-* 04: 01 / \\
* 13: 01-* 06: 03\end{array}$ & $\mathrm{SH}$ & RE & DD \\
\hline 9 & 28 & M & Yes & 20.9 & 600 & 6.0 & 0.2 & Negative & $\begin{array}{l}* 08: 03-* 06: 01 / \\
* 04: 05-* 04: 01\end{array}$ & $\mathrm{GH}$ & RR & DD \\
\hline 10 & 32 & $\mathrm{~F}$ & Yes & 19.2 & 540 & 6.3 & 0.1 & Negative & $\begin{array}{l}* 13: 02-* 06: 04 / \\
* 13: 02-* 06: 09\end{array}$ & SS & $\mathrm{EE}$ & VV \\
\hline 11 & 42 & M & Yes & 27.7 & 567 & 6.6 & 0.1 & Negative & $\begin{array}{l}* 04: 05-* 04: 01 / \\
* 07: 01-* 02: 01\end{array}$ & $\mathrm{YH}$ & RR & DA \\
\hline
\end{tabular}

All of the clinical characteristics were measured during initial presentation of diabetic ketoacidosis.

HLA, human leukocyte antigen. GAD, glutamic acid decarboxylase. $F$, female. $M$, male.

${ }^{a}$ Amino acid abbreviation is shown for each position. 
imputation quality score of $\mathrm{r}^{2}>0.3$ was used as the cut-off. Among the 11 fulminant T1DM cases, we validated the HLA-DRB1 and HLA-DQB1 imputed genotype in two participants using the AlleleSEQR HLA Sequencing Kit (Atria Genetics, South San Francisco, CA, USA) and it revealed identical results. For association testing we used the best-guessed genotype in $0 / 1 / 2$ format.

\section{Statistical analysis}

As we only had genotype data from a small number $(\mathrm{n}=$ 11) of fulminant T1DM cases, we tried to describe the HLA genotype and haplotype of each individual, as well as the recently reported amino acid residues at three major positions in the HLA-DR and HLA-DQ molecules [5]. For the case-control analysis, 11 fulminant T1DM cases and 413 Korean Reference Panel controls were compared [6]. Subject having two copies of a specific variant was classified as Present/Present, having only one copy was defined as Present/Absent, and having none of the variants was considered Absent/Absent. Fisher's exact test was performed to compare the frequency of HLA haplotype or variant in each locus and Cochran-Armitage trend test was performed to examine the linear trend of three types, Present/Present, Present/Absent, and Absent/Absent between cases and controls. A p-value of less than 0.05 was regarded to be statistically significant. Assuming a type 1 error rate of 0.05 and a variant frequency of 0.27 in 11 cases and 0.08 in 413 controls, our study had a limited statistical power of 0.43 using Fisher's exact text.

\section{Results}

\section{Clinical characteristics}

The clinical characteristics of the fulminant T1DM cases are described in Table 1 . The mean age was $36.6 \pm 9.8 \mathrm{y}$, and mean body mass index was $22.0 \pm 3.4 \mathrm{~kg} / \mathrm{m}^{2}$. All participants had an HbA1c level of less than $7.0 \%$ except one patient who had HbAlc of $8.1 \%$ at initial presentation of diabetic ketoacidosis. There was absolute deficiency in insulin secretion in all of the participants and none of the participants had anti-glutamic acid decarboxylase (GAD) autoantibody. The HLA-DRB1 - HLA-DQB1 diplotype of the four-digit classical allele of each individual is described in Table 1 . The amino acid residues at HLA-DR $\beta 1$ position 13 , HLA-DR $\beta 1$ position 71, and HLA-DQ $\beta 1$ position 57 are also shown in Table 1.

\section{HLA-DRB1-HLA-DQB1 haplotype analysis}

The HLA-DRB1 - HLA-DQB1 haplotype frequencies in 11 fulminant T1DM cases and 413 Korean Reference Panel subjects are shown in Table 2. We focused on five haplotypes that were reported to be significantly associated with either increased (HLA-DRB1*04:05-HLA-DQB1*04:01, HLADRB1*09:01-HLA-DQB1*03:03) or decreased (HLADRB1*01:01-HLA-DQB1*05:01, HLA-DRB1*15:02-HLADQB1*06:01, and HLA-DRB1*08:03 - HLA-DQB1*06:01) risk of fulminant T1DM in Japanese. We found that the frequency of the HLA-DRB1*04:05-HLA-DQB1*04:01 haplotype was 0.27 in Korean fulminant T1DM cases and 0.08 in the Korean Reference Panel. This haplotype was significantly associated with a risk of fulminant T1DM by

Table 2. Haplotype frequency and association with fulminant T1DM

\begin{tabular}{|c|c|c|c|c|c|c|c|c|c|c|c|}
\hline \multirow{2}{*}{$\begin{array}{c}\text { HLA-DRB1- } \\
\text { HLA-DQB1 } \\
\text { Haplotype }\end{array}$} & \multicolumn{4}{|c|}{ Fulminant T1DM $(n=11)$} & \multirow{2}{*}{$\begin{array}{c}\text { Korean } \\
\text { Present/ } \\
\text { Present }\end{array}$} & \multirow{2}{*}{$\begin{array}{c}\text { Reference } \\
\begin{array}{c}\text { Present/ } \\
\text { Absent }\end{array}\end{array}$} & \multicolumn{2}{|c|}{ e Panel $(n=413)$} & \multicolumn{2}{|c|}{ Fisher's exact test } & \multirow{2}{*}{$\begin{array}{c}\text { Cochran- } \\
\text { Armitage } \\
\text { trend test }\end{array}$} \\
\hline & $\begin{array}{l}\text { Present/ } \\
\text { Present }\end{array}$ & $\begin{array}{c}\text { Present/ } \\
\text { Absent }\end{array}$ & $\begin{array}{l}\text { Absent/ } \\
\text { Absent }\end{array}$ & Frequency & & & $\begin{array}{c}\text { Absent/ } \\
\text { Absent }\end{array}$ & Frequency & $\begin{array}{c}\text { OR } \\
(95 \% \mathrm{Cl})\end{array}$ & p-value & \\
\hline$* 04: 05-* 04: 01$ & 1 & 4 & 6 & 0.27 & 5 & 59 & 349 & 0.08 & $\begin{array}{c}4.11 \\
(1.56 \sim 10.86)\end{array}$ & 0.009 & 0.003 \\
\hline$* 08: 03-* 06: 01$ & 0 & 3 & 8 & 0.14 & 1 & 53 & 359 & 0.07 & $\begin{array}{c}2.21 \\
(0.64 \sim 7.71)\end{array}$ & 0.19 & 0.19 \\
\hline$* 09: 01-* 03: 03$ & 0 & 1 & 10 & 0.05 & 4 & 59 & 350 & 0.08 & $\begin{array}{c}0.54 \\
(0.07 \sim 4.08)\end{array}$ & 1.00 & 0.36 \\
\hline$* 15: 02-* 06: 01$ & 0 & 1 & 10 & 0.05 & 0 & 12 & 401 & 0.01 & $\begin{array}{c}3.23 \\
(0.40 \sim 26.01)\end{array}$ & 0.29 & 0.29 \\
\hline$* 01: 01-* 05: 01$ & 0 & 0 & 11 & 0.00 & 2 & 48 & 363 & 0.06 & $\begin{array}{c}0.33 \\
(0.02 \sim 5.48)\end{array}$ & 0.39 & 0.23 \\
\hline
\end{tabular}

Fisher's exact test was performed based on haplotype frequencies in cases and controls. Cochran-Armitage trend test was performed based on diplotype frequencies in cases and controls.

T1DM, type 1 diabetes. OR, odds ratio. $\mathrm{Cl}$, confidence interval. 
Fisher's exact test (OR, 4.11; 95\% confidence interval [CI], 1.56 to $10.86 ; \mathrm{p}=0.009)$. None of the other haplotypes showed a significant association presumably due to the limited statistical power.

\section{Three amino acid positions in the HLA-DR and HLA-DQ molecules}

The frequency of amino acid residues at HLA-DR $\beta 1$ position 13 and position 71, and HLA-DQ $\beta 1$ position 57 and their association with fulminant T1DM are shown in Table 3. A histidine residue at HLA-DR $\beta 1$ position 13 showed marginal association with fulminant T1DM by Fisher's exact test (OR, 2.45; 95\% CI, 1.01 to 5.94; $\mathrm{p}=$ $0.054)$ and Cochran-Armitage trend test $(\mathrm{p}=0.034)$. However, none of the other amino acid residues at the three positions showed a significant association with fulminant T1DM.

\section{Discussion}

In this study, we have investigated the HLA genotype and haplotype in 11 fulminant T1DM cases and compared its frequency with that of the general population. We have found that the HLA-DRB1*04:05-HLA-DQB1*04:01 haplotype is significantly associated with increased risk of fulminant T1DM in Koreans. In addition, a histidine residue at HLA-DR $\beta 1$ position 13 showed marginal association with fulminant T1DM. To the best of our knowledge, this is the first study to investigate the HLA-DR4-HLA-DQ4 haplotype in fulminant T1DM patients from a population other than Japanese. We also investigated for the first time the association between amino acid residues in three positions of the HLA-DR and HLA-DQ molecules and the risk of fulminant T1DM.

It is well known that HLA genes account for a significant proportion of the susceptibility to T1DM [12]. The complex genetic structure of HLA loci arising from recombination, gene conversion, and natural selection has been a hurdle in

Table 3. Three amino acid positions at HLA-DR and HLA-DQ and association with fulminant T1DM

\begin{tabular}{|c|c|c|c|c|c|c|c|c|c|c|c|c|}
\hline & \multirow{2}{*}{$\begin{array}{c}\text { Amino } \\
\text { acid }\end{array}$} & \multicolumn{4}{|c|}{ Fulminant T1DM $(n=11)$} & \multicolumn{4}{|c|}{ Korean reference panel $(n=413)$} & \multicolumn{2}{|c|}{ Fisher's exact test } & \multirow{2}{*}{$\begin{array}{c}\begin{array}{l}\text { Cochran- } \\
\text { Armitage } \\
\text { trend tes }\end{array} \\
p_{\text {trend }}\end{array}$} \\
\hline & & $\begin{array}{l}\text { Present/ } \\
\text { Present }\end{array}$ & $\begin{array}{l}\text { Present/ } \\
\text { Absent }\end{array}$ & $\begin{array}{l}\text { Absent/ } \\
\text { Absent }\end{array}$ & Frequency & $\begin{array}{l}\text { Present/ } \\
\text { Present }\end{array}$ & $\begin{array}{c}\text { Present/ } \\
\text { Absent }\end{array}$ & $\begin{array}{l}\text { Absent/ } \\
\text { Absent }\end{array}$ & Frequency & $\begin{array}{c}\text { OR } \\
(95 \% \mathrm{Cl})\end{array}$ & p-value & \\
\hline \multirow[t]{6}{*}{$\begin{array}{l}\text { HLA-DR } \beta 1 \\
\text { Position } 13\end{array}$} & $\mathrm{H}$ & 1 & 6 & 4 & 0.36 & 10 & 136 & 266 & 0.19 & $\begin{array}{c}2.45 \\
(1.01 \sim 5.94)\end{array}$ & 0.054 & 0.034 \\
\hline & $\mathrm{S}$ & 2 & 1 & 8 & 0.23 & 29 & 168 & 215 & 0.27 & $\begin{array}{c}0.78 \\
(0.28 \sim 2.14)\end{array}$ & 0.81 & 0.62 \\
\hline & G & 0 & 5 & 6 & 0.23 & 11 & 126 & 275 & 0.18 & $\begin{array}{c}1.34 \\
(0.49 \sim 3.70)\end{array}$ & 0.57 & 0.56 \\
\hline & Y & 0 & 2 & 9 & 0.09 & 1 & 57 & 354 & 0.07 & $\begin{array}{c}1.30 \\
(0.30 \sim 5.68)\end{array}$ & 0.67 & 0.72 \\
\hline & $\mathrm{F}$ & 0 & 1 & 10 & 0.05 & 18 & 102 & 292 & 0.17 & $\begin{array}{c}0.24 \\
(0.03 \sim 1.78)\end{array}$ & 0.15 & 0.15 \\
\hline & $R$ & 0 & 1 & 10 & 0.05 & 5 & 87 & 320 & 0.12 & $\begin{array}{c}0.36 \\
(0.05 \sim 2.68) \\
\end{array}$ & 0.50 & 0.29 \\
\hline \multirow[t]{4}{*}{$\begin{array}{l}\text { HLA-DR } \beta 1 \\
\text { Position } 71\end{array}$} & $R$ & 6 & 3 & 2 & 0.68 & 225 & 169 & 18 & 0.75 & $\begin{array}{c}0.71 \\
(0.29 \sim 1.77)\end{array}$ & 0.46 & 0.44 \\
\hline & $\mathrm{E}$ & 1 & 2 & 8 & 0.18 & 4 & 89 & 319 & 0.12 & $\begin{array}{c}1.67 \\
(0.55 \sim 5.03)\end{array}$ & 0.32 & 0.36 \\
\hline & K & 0 & 2 & 9 & 0.09 & 0 & 20 & 392 & 0.02 & $\begin{array}{c}4.02 \\
(0.88 \sim 18.38)\end{array}$ & 0.11 & NA \\
\hline & A & 0 & 1 & 10 & 0.05 & 2 & 84 & 326 & 0.11 & $\begin{array}{c}0.40 \\
(0.05 \sim 3.00) \\
\end{array}$ & 0.72 & 0.34 \\
\hline \multirow[t]{4}{*}{$\begin{array}{l}\text { HLA-DQ } \beta 1 \\
\text { Position } 57\end{array}$} & D & 7 & 2 & 2 & 0.73 & 143 & 197 & 69 & 0.59 & $\begin{array}{c}1.85 \\
(0.72 \sim 4.78)\end{array}$ & 0.27 & 0.20 \\
\hline & A & 0 & 3 & 8 & 0.14 & 17 & 124 & 268 & 0.19 & $\begin{array}{c}0.66 \\
(0.19 \sim 2.26)\end{array}$ & 0.78 & 0.51 \\
\hline & V & 1 & 1 & 9 & 0.14 & 10 & 132 & 267 & 0.19 & $\begin{array}{c}0.69 \\
(0.20 \sim 2.37)\end{array}$ & 0.78 & 0.54 \\
\hline & $S$ & 0 & 0 & 11 & 0.00 & 0 & 25 & 384 & 0.03 & $\begin{array}{c}0.69 \\
(0.04 \sim 11.73)\end{array}$ & 1.00 & $\mathrm{NA}$ \\
\hline
\end{tabular}

Fisher's exact test was performed based on allele frequencies in cases and controls. Cochran-Armitage trend test was performed based on genotype frequencies in cases and controls.

T1DM, type 1 diabetes. OR, odds ratio. $\mathrm{Cl}$, confidence interval. NA, not applicable. 
identifying the precise genetic predisposition [13]. However, the linkage disequilibrium stretches for a long-range in the HLA loci and it is possible to determine accurate HLA genotype, and haplotype using common single nucleotide variations [14]. The SNP2HLA software has been shown to be a powerful tool in imputing HLA genotypes in large-scale genome-wide association studies [5]. However, it has not been applied to whole exome sequence genotype data. We have applied SNP2HLA in 11 cases of fulminant T1DM cases and successfully determined HLA alleles, haplotypes, and amino acid residues. The classic alleles of HLA-DRB1 and HLA-DQB1 were determined by direct genotyping of two participants of fulminant T1DM and the results were consistent with the imputed genotypes.

The most well-known HLA haplotype associated with fulminant T1DM is HLA-DRB1*04:05-HLA-DQB1*04:01. In a large-scale association analysis in Japanese, it increased the risk of fulminant T1DM by 2.9 folds. This haplotype was also associated with either acute onset or slowly progressive T1DM in Japanese [15]. In this study, we confirmed this finding and the haplotype was associated with a 4.11 fold increased risk in Koreans. In the Korean Reference Panel, the HLA-DRB1 $*$ 04:05 allele and HLA-DQB1*04:01 allele were in perfect linkage disequilibrium $\left(r^{2}=1.0\right)$. Both the HLADRB1*04:05 allele and HLA-DQB1*04:01 allele were also significantly associated with the risk of fulminant T1DM ( $\mathrm{p}$ $=0.011$ by Fisher's exact test). Although there are other haplotypes reported to be associated with fulminant T1DM, we had limited statistical power to obtain a sound conclusion.

In a recent report investigating the association of T1DM with amino acid residues at three positions of the HLA-DR and HLA-DQ molecules, HLA-DR $\beta 1$ position 13 and position 71 , and HLA-DQ $\beta 1$ position 57 explained a significant portion of phenotypic variation conferred by the HLA-DRB1-HLA-DQA1-HLA-DQB1 locus. We have identified that a histidine residue at HLA-DR $\beta 1$ position 13 is marginally associated with a 2.45 fold increased risk of fulminant T1DM. In Europeans this residue was associated with a 3.64 fold increased risk of T1DM [5]. This residue lines the P4 pocket of the HLA-DR molecule and was reported to be associated with rheumatoid arthritis [16]. It could be speculated that it plays a role in the recognition of autoantigens and autoimmunity [5]. However, it is difficult to have a direct comparison of our results with that of T1DM in Europeans, and it is not known whether these amino acid residues in the three positions are also major risk determinants of T1DM in East Asians. In addition, the similarities in genetic predisposition between fulminant T1DM and other types of T1DM require further investigation. It has been suggested that the genetic predis- position conferred by the HLA locus could be different between fulminant T1DM and other types of T1DM in Japanese [15].

In conclusion, we have investigated the HLA genotype and haplotype in 11 Korean fulminant T1DM cases and provide evidence that HLA-DRB1*04:05-HLA-DQB1*04:01 is an important genetic risk factor of fulminant T1DM. There is suggestive evidence that a histidine residue at HLA-DR $\beta 1$ position 13 which lines the P4 pocket of the HLA-DR molecule, might increase the risk of fulminant T1DM in Koreans. Further large-scale investigation is required to confirm our findings.

\section{Acknowledgments}

This study was supported by a grant of the Korea Health Technology R\&D Project, Ministry of Health and Welfare, Republic of Korea (HI14C0060) and of the research grant from the Seoul National University Hospital (04-2013-1000).

\section{References}

1. Imagawa A, Hanafusa T, Awata T, Ikegami H, Uchigata Y, Osawa $\mathrm{H}$, et al. Report of the Committee of the Japan Diabetes Society on the Research of Fulminant and Acute-onset Type 1 Diabetes Mellitus: new diagnostic criteria of fulminant type 1 diabetes mellitus (2012). J Diabetes Investig 2012;3:536-539.

2. Imagawa A, Hanafusa T, Miyagawa J, Matsuzawa Y. A novel subtype of type 1 diabetes mellitus characterized by a rapid onset and an absence of diabetes-related antibodies. Osaka IDDM Study Group. N Engl J Med 2000;342:301-307.

3. Cho YM, Kim JT, Ko KS, Koo BK, Yang SW, Park MH, et al. Fulminant type 1 diabetes in Korea: high prevalence among patients with adult-onset type 1 diabetes. Diabetologia 2007; 50:2276-2279.

4. Tsutsumi C, Imagawa A, Ikegami H, Makino H, Kobayashi T, Hanafusa T. Class II HLA genotype in fulminant type 1 diabetes: A nationwide survey with reference to glutamic acid decarboxylase antibodies. J Diabetes Investig 2012;3:62-69.

5. Hu X, Deutsch AJ, Lenz TL, Onengut-Gumuscu S, Han B, Chen WM, et al. Additive and interaction effects at three amino acid positions in HLA-DQ and HLA-DR molecules drive type 1 diabetes risk. Nat Genet 2015;47:898-905.

6. Kim K, Bang SY, Lee HS, Bae SC. Construction and application of a Korean reference panel for imputing classical alleles and amino acids of human leukocyte antigen genes. PLoS One 2014;9:e112546.

7. Li H, Durbin R. Fast and accurate short read alignment with Burrows-Wheeler transform. Bioinformatics 2009;25:17541760.

8. McKenna A, Hanna M, Banks E, Sivachenko A, Cibulskis K, Kernytsky A, et al. The Genome Analysis Toolkit: a MapReduce framework for analyzing next-generation DNA sequencing data. Genome Res 2010;20:1297-1303. 
9. Jia X, Han B, Onengut-Gumuscu S, Chen WM, Concannon PJ, Rich SS, et al. Imputing amino acid polymorphisms in human leukocyte antigens. PLoS One 2013;8:e64683.

10. Browning SR, Browning BL. Rapid and accurate haplotype phasing and missing-data inference for whole-genome association studies by use of localized haplotype clustering. Am J Hum Genet 2007;81:1084-1097.

11. Okada Y, Kim K, Han B, Pillai NE, Ong RT, Saw WY, et al. Risk for ACPA-positive rheumatoid arthritis is driven by shared HLA amino acid polymorphisms in Asian and European populations. Hum Mol Genet 2014;23:6916-6926.

12. Erlich H, Valdes AM, Noble J, Carlson JA, Varney M, Concannon P, et al. HLA DR-DQ haplotypes and genotypes and type 1 diabetes risk: analysis of the type 1 diabetes genetics consortium families. Diabetes 2008;57:1084-1092.
13. Traherne JA. Human MHC architecture and evolution: implications for disease association studies. Int J Immunogenet 2008;35:179-192.

14. de Bakker PI, McVean G, Sabeti PC, Miretti MM, Green T, Marchini J, et al. A high-resolution HLA and SNP haplotype map for disease association studies in the extended human MHC. Nat Genet 2006;38:1166-1172.

15. Kawabata Y, Ikegami H, Awata T, Imagawa A, Maruyama T, Kawasaki E, et al. Differential association of HLA with three subtypes of type 1 diabetes: fulminant, slowly progressive and acute-onset. Diabetologia 2009;52:2513-2521.

16. Raychaudhuri S, Sandor C, Stahl EA, Freudenberg J, Lee HS, Jia $\mathrm{X}$, et al. Five amino acids in three HLA proteins explain most of the association between MHC and seropositive rheumatoid arthritis. Nat Genet 2012;44:291-296. 